\title{
STRINGENT GLYCEMIC CONTROL IS STILL THE KEY TO EVADE DIABETIC RETINOPATHY.
}

1. MBBS, M.Phil

Assistant Professor Biochemistry

Fatima Jinnah Dental College,

Karachi, Pakistan.

2. MBBS, M.Phil

Associate Professor Biochemistry Liaquat College of Medicine

Dentistry, Karachi, Pakistan.

3. MBBS, M.Phil

Demonstrator Biochemistry

Bolan Medical College, Quetta, Pakistan.

4. MBBS, M.Phil

Assistant Professor Physiology

Dow International Medical College,

DUHS, Karachi, Pakistan.

Correspondence Address:

Dr. Syed Munawar Alam,

Department of Biochemistry,

Fatima Jinnah Dental College,

Karachi, Pakistan.

dsmalam@hotmail.com

Article received on:

27/08/2019

Accepted for publication:

25/10/2019

\begin{abstract}
Syed Munawar Alam 1 , Sagheer Ahmed $^{2}$, Shazia Bano ${ }^{3}$, Shahneela Perveen ${ }^{4}$
\end{abstract}
ABSTRACT... Objectives: The aim of this study was to evaluate the major determinants of diabetic retinopathy. Study Design: Cross sectional, case control study. Setting: Department of Biochemistry, Basic Medical Sciences Institute, Jinnah Post Graduate Medical Centre, Karachi. Period: March 2015 to April 2016. Material \& Methods: Ethical approval was taken from the Institutional Review Board of JPMC. A total of 208 people including type 2 diabetic patients and healthy control subjects; of male gender, aged between $\geq 30$ years and $\leq 60$ years were recruited and assigned to four study groups. Each group comprise of 52 individuals, depending on the ophthalmoscopy findings, i.e. healthy controls, diabetic without retinopathy (NDR), diabetic with non-proliferative diabetic retinopathy (NPDR) and diabetic with proliferative diabetic retinopathy (PDR). Fasting blood sugar was estimated using GOD-PAP method, while HbA1c was estimated by HPLC method. Data was analyzed on SPSS software version 16. Results: Diabetics with Diabetic Retinopathy had a poor glycemic control as compare to Diabetics without Diabetic Retinopathy (FBS; $109.12 \pm 13.81$ vs. $184.29 \pm 40.07$ vs. $188.6 \pm$ 47.68 vs. $217.06 \pm 62.33 ; p$-value $=0.001)(\mathrm{HbA} 1 \mathrm{c} ; 6.73 \pm 0.56$ vs. $8.40 \pm 1.77$ vs. $9.71 \pm$ 1.85 vs. $14.91 \pm 3.87$; p-value $=0.001$ ). For Diabetic Retinopathy the odds ratio of glycemic control i.e. FBS was observed as 1.019 \& HbA1c was recorded as 1.561; which was statistically significant. Conclusion: Glycemic indicators; including FBS and $\mathrm{HbA1c}$, are found to be the major determinants of Diabetic Retinopathy in our study.

Key words: Determinant of Diabetic Retinopathy, Diabetic Retinopathy, Glycemic Control.

Article Citation: Alam SM, Ahmed S, Bano S, Perveen S. Stringent glycemic control is still the key to evade diabetic retinopathy. Professional Med J 2020; 27(5):1011 1016. DOI: 10.29309/TPMJ/2020.27.05.4077

\section{INTRODUCTION}

Diabetes mellitus is a cluster of metabolic illnesses patented by hyperglycemia resulting from deficiencies in either insulin secretion or resistance to its peripheral action, or both. ${ }^{1}$ Evidently; diabetes complications are the profound contributors of its morbidity as well as mortality. Though there is a whole range of metabolic complications of diabetes as well yet the vascular versions of diabetes complications are sub-classified into macro-vascular complications; comprising of coronary artery disease, peripheral arterial disease and stroke and microvascular complications including diabetic nephropathy, neuropathy and retinopathy. 2,3,4 Glycaemia and diabetes are an escalating global hazard with an estimated 347 million people already suffering worldwide and by the end of next decade the estimated number is expected to have risen to half a billion. ${ }^{5}$ It would be worth mentioning here that diabetic mortality is strongly and closely associated with the socio-economic parameters of the region specifically 4 out of 5 diabetic deaths occur in low- and middle-income countries. ${ }^{6}$ In the developing countries, the majority of people with diabetes belong to the age bracket of 45 to 64 years. ${ }^{7}$ Pakistan is also confronting a threatening growth in the incidence and prevalence of diabetes which is reaching epidemic proportions, with already more than 7 million people with diabetes; and more so it is expected to rise to 11.4 million by the end of next decade. ${ }^{8}$ Global data on visual impairment in the year 2002 assessed the number of people with legal blindness to 37 million and diabetic retinopathy contributes approximately $4.8 \%$ in the overall disease burden. ${ }^{9}$ However, in 2010; globally, the number of people of all ages visually impaired is apprised to be 285 million, of 
whom 39 million are considered blind. ${ }^{10}$ Without extra interventions, the global number of blind individuals would increment up to 76 million in 2020. ${ }^{11,12}$

Diabetic retinopathy is the major most contributor in the causes of new cases of blindness among adults aged $20-74$ years. ${ }^{13}$ A phenomenal 25 fold massive increase in the relative risk of blindness has been documented in diabetics as against their non-diabetic counter parts. ${ }^{14}$

The prevalence of diabetic retinopathy is documented $17.6 \%$ in India during CURES eye study. ${ }^{15}$ A global inclusive estimation of prevalence of diabetic retinopathy revealed that one third of the diabetics were having some sort of retinopathy, moreover approximately $10 \%$ of them were shown to have the proliferative type which may lead to blindness eventually. ${ }^{16,17}$

Diabetic prevalence in Asian-Americans was found to be highest in South Asian ethnic group. ${ }^{18,19}$ Even in Europe it has been reported that the prevalence of type 2 diabetes mellitus is more in the ethnic minorities as against the indigenous population. ${ }^{20}$ More over in China a surge of two folds has been observed in the prevalence of type 2 diabetes mellitus over the time period of two decades. ${ }^{21}$

While the case in Pakistan is no different as the prevalence of diabetic retinopathy here, in community based clinics were found to be $15.7 \% .^{22}$ In fact recently the data generated locally indicates a prevalence of diabetic retinopathy as high as $26 \% .^{23}$ Diabetic retinopathy is characterized by loss of capillary cells leading to increased vaso-permeability, ischemia and hypoxia that trigger the excessive formation of new blood vessels in the retina; possibly leading to vitreous hemorrhage and eventually retinal detachment. ${ }^{24}$ In this context; current research work, is an attempt to probe into the major determinants of diabetic retinopathy; especially focusing its proliferative type.

\section{MATERIAL \& METHODS}

This proposed research was perceived and executed as a hospital based, cross sectional, case control study. The time frame from perception to execution of this study protocol was one year i.e. from March 2015 to April 2016. The study was accomplished in the Department of Biochemistry, Basic Medical Sciences Institute, Jinnah Post Graduate Medical Centre, Karachi, in collaboration with the affiliated tertiary care hospital (Jinnah Postgraduate Medical Centre).

Our study population comprised of males; who were already diagnosed patients of type 2 diabetes mellitus, irrespective of their glycemic control. In addition, demographically matched, healthy male subjects were also recruited in the study; as control. Ethical approval of this research was sought from the IRB of JPMC. An informed written consent was also obtained from all the subjects, before recruiting them in the study. Sample size was calculated using open epi calculator, taking Jamal et al 2006 as the reference study, and it was determined to be 208. All the recruited study subjects were divided into four study groups, based on the ophthalmoscopy findings as well as glycemic indicators; i.e. Control Group A, Healthy non-diabetic subjects.

Case Group B, Patients with type 2 diabetes mellitus without diabetic retinopathy. Case Group C, Patients with type 2 diabetes mellitus along with non-proliferative diabetic retinopathy. Case Group D, Patients with type 2 diabetes mellitus along with proliferative diabetic retinopathy. Fasting Blood Glucose (mg/dl) was measured by enzymatic colorimetric method. ${ }^{25}$ HBA1c (\%) was determined by HPLC method. ${ }^{26}$ Ophthalmic examination of all the recruited study subjects as well as patients were conducted in the out patients department of JPMC; by an ophthalmologist. After observing complete pupil dilatation, funduscopic examination of each eye was done in dark room with Keeler's Ophthalmoscope. ${ }^{27}$ Presence or absence of signs of retinopathy in each eye was recorded accordingly. An ophthalmologist graded these signs according to the Diabetic Retinopathy Disease Severity Scale as catalogued by American Academy of Ophthalmology. The data was entered in the Microsoft excel sheet which was exported into the statistical software SPSS 
Version 16. The continuous data was entered as mean + SD and comparison between more than two variables was done by ANOVA. Group comparisons were done by applying ANOVA. Binary logistic regression was also performed to find out the association of predictor variables with diabetic retinopathy. The statistical tests were considered significant at the $p$ values of $<5 \%$.

\section{RESULTS}

Comparison of glycemic control (FBS\& $\mathrm{HbA1c}$ ) among the four groups was observed as statistically significant at $95 \%$ confidence interval. The post hoc analysis showed that the mean FBS significantly differs between Controls and Diabetic patients without Retinopathy (109.12 \pm 13.81 vs. $184.29 \pm 40.07$; $p$-value $=0.001$; Controls and Patients with Non Proliferative Diabetic Retinopathy (109.12 \pm 13.82 vs. $188.6 \pm$ 47.68; $p$-value $=0.001$ ); Control and Proliferative Diabetic Retinopathy (109.12 \pm 13.83 vs. 217.06 \pm 62.23; p-value $=0.001$ ); Diabetic patients without Retinopathy and patients with Proliferative Diabetic Retinopathy (184.29 \pm 40.07 vs. 217.06 \pm 62.24; p-value $=0.003$ ); Patients with Non Proliferative Diabetic Retinopathy and Patients with Proliferative Diabetic Retinopathy (188.6 \pm 47.68 vs. $217.06 \pm 62.25$; $p$-value $=0.016$ ) (Figuere-1).

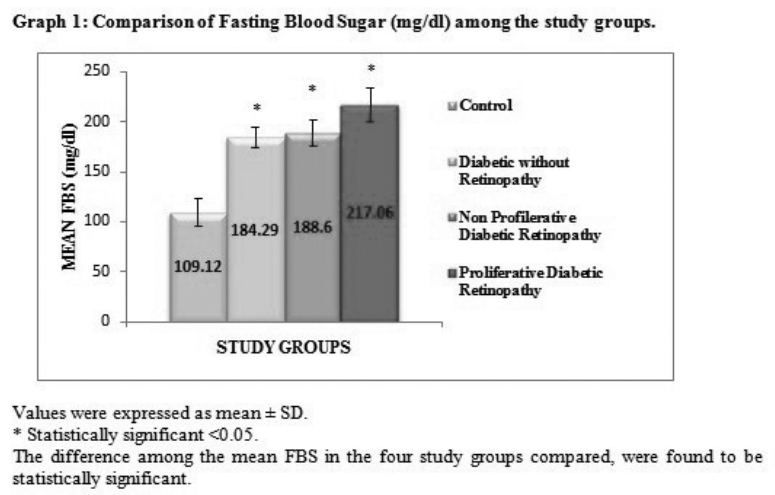

Figure-1. Comparison of fasting blood sugar (mg/dl) among the study groups.
Controls and Patients with Non Proliferative Diabetic Retinopathy $(6.73 \pm 0.56$ vs. $9.71 \pm$ 1.85; $p$-value $=0.001$; ; Control and Proliferative Diabetic Retinopathy $(6.73 \pm 0.56$ vs. $14.91 \pm$ 3.87; $p$-value $=0.001$ ); Diabetic patients without Retinopathy and patients with Non Proliferative Diabetic Retinopathy $(8.4 \pm 1.77$ vs. $9.71 \pm$ 1.85; $p$-value $=0.045$ ); Diabetic patients without Retinopathy and patients with Proliferative Diabetic Retinopathy $(8.4 \pm 1.77$ vs. $14.91 \pm 3.87$; p-value $=0.001)$; Patients with Non Proliferative Diabetic Retinopathy and Patients with Proliferative Diabetic Retinopathy $(9.71 \pm 1.85$ vs. $14.91 \pm$ 3.87; $p$-value $=0.001)$ (Figure-2).

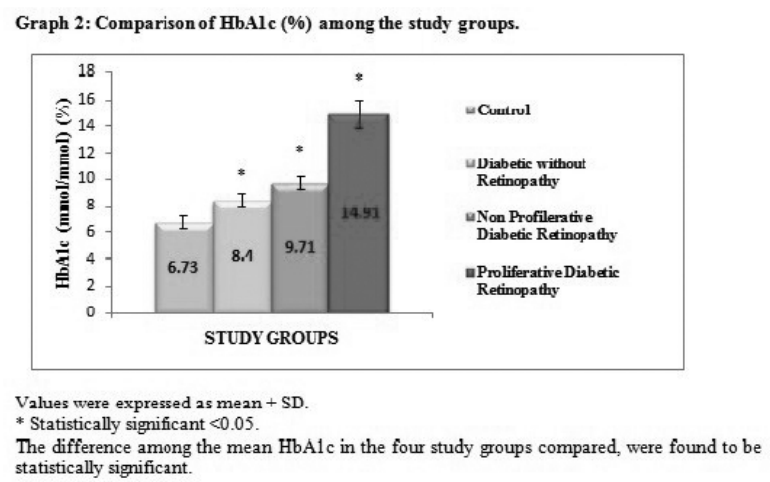

Figure-2. Comparison of HbA1c (\%) among the study groups.

To identify the risk factors for Diabetic Retinopathy Regression analysis was performed. The outcome variable of interest was Diabetic retinopathy (Yes/ No). Since the outcome variable was binary the regression analysis of choice was Binary Logistic Regression. The binary logistic regression revealed that FBS \& HbA1c were significant predictors of Diabetic Retinopathy, The Odds ratio (at $95 \%$ confidence interval) for Fasting Blood Sugar was 1.019 (1.006 - 1.031) with $\mathrm{p}$-value $=0.004$. The Odds ratio (at 95\% confidence interval) for glycosylated hemoglobin was $1.561(1.157-2.107)$ with $p$-value $=0.004$ (Table-l).
The post hoc analysis also showed that the mean $\mathrm{HbA1c}$ significantly differs between Controls and Diabetic patients without Retinopathy $(6.73 \pm 0.56$ vs. $8.4 \pm 1.77 ; p$-value $=0.005)$; 


\begin{tabular}{|c|c|c|c|c|c|}
\hline & \multirow{2}{*}{ df } & \multirow{2}{*}{ Sig. } & \multirow{2}{*}{$\operatorname{Exp}(B)$} & \multicolumn{2}{|c|}{ 95\% C .for EXP(B) } \\
\hline & & & & Lower & Upper \\
\hline FBS & 1 & $.004^{*}$ & 1.019 & 1.006 & 1.031 \\
\hline Constant & 1 & 0.000 & 0.000 & & \\
\hline \multicolumn{6}{|c|}{$\begin{array}{l}\text { Table-I. Binary logistic regression of diabetic retinopathy with glycemic control indicators. } \\
\text { Values were expressed as mean } \pm \text { SD. } \\
\text { * Statistically significant }<0.05\end{array}$} \\
\hline
\end{tabular}

The odd ratio of significant predictors of Diabetic Retinopathy at $95 \%$ confidence interval showed that the increase in the FBS and $\mathrm{HbA} 1 \mathrm{c}$ increases the odds of developing Diabetic Retinopathy.

\section{DISCUSSION}

Predictors and determinants of diabetic retinopathy are under constant probing in order to counterthis preventablecause ofvisual impairment and blindness. In this regard; along with the duration of diabetes mellitus and hypertension, poor glycemic control is documented as a major determinant of diabetic retinopathy. ${ }^{28}$ In fact on its own, the poor glycemic control has been demonstrated as a major determinant of diabetic retinopathy even when the duration of diabetes is relatively short. ${ }^{29}$

Moreover it has also been observed that blood sugar level indicates transitory glycemic control while in contrast glycosylated hemoglobin (HbA1c) reflects a more sustained glycemic control as well as patient compliance. ${ }^{30}$ Especially; in our study; HbA1c was observed to predict the Diabetic Retinopathy outcome more profoundly; approximately $56 \%$ increase risk of Diabetic Retinopathy per percent increase in $\mathrm{HbA} 1 \mathrm{c}$.

In concurrence to the findings in our study it was also established that baseline glycemic level of $\mathrm{HbA}_{1} \mathrm{c}$ were more profound in predicting diabetic retinopathy as an outcome variable as against the follow up levels; something which is credited to the metabolic memory. ${ }^{31}$

Furthermore same trend was also observed in the CURES eye study ${ }^{32}$, where a linear affinity between the prevalence of retinopathy with the increase in quartiles of $\mathrm{HbA1c}$ was observed; specifically for every $2 \%$ elevation of $\mathrm{HbA} 1 \mathrm{c}$, the risk for diabetic retinopathy increased by a factor of 1.7 .

Similar observations were reported in earlier research established facts that despite the threefold risk of hypoglycemia; intense glycemic control decreased the mean risk of developing retinopathy by up to 76 percent. $^{33}$ Also comparable findings were observed in UKPDS Group; specifically for every percent decrease in $\mathrm{HbA} 1 \mathrm{c}$ there was $35 \%$ reduction in the diabetic retinopathy risk. Moreover the overall risk of microvasculature complication reduced by $25 \%$ in patients receiving intense glycemic control therapy. ${ }^{34}$

Though the cross sectional design of our study was a major limitation and it would have been more convincing to documents the factual findings on a more temporal basis. Yet as these findings are in scientific alignment with the credible published data, we can safely assume that stringent and intensive glycemic control can not only prevent but also delay the progression of diabetic retinopathy. ${ }^{35}$

\section{CONCLUSION}

Glycemic indicators; including fasting blood glucose (FBS) and glycosylated hemoglobin $(\mathrm{HbA1c})$ are establish as the major predictors of diabetic retinopathy in our study. This conclusion reflects that in order to prevent diabetic retinopathy we actually need to be more aggressive about the glycemic control even when hypoglycemia is a limiting factor for the intervention.

\section{Copyright $\odot 25$ Oct, 2019.}




\section{REFERENCES}

1. American Diabetes Association. Diagnosis and classification of diabetes mellitus. Dia Care. 2018; 41: S13-S27. doi:https://doi.org/10.2337/dc18-S002.

2. Desouza CV, Bolli GB, Fonesca V. Hypoglycemia, diabetes, and cardiovascular events. Dia Care. 2010; 33:1389-1394. doi:10.2337/dc09-2082.

3. Fonseca VA. Defining and characterizing the progression of type 2 diabetes. Dia Care. 2009; 32:151-156. doi: 10.2337/dc09-S301.

4. Fowler M J. Microvascular and macrovascular complications of diabetes. Clin Dia. 2008; 26:77-82. doi:https://doi.org/10.2337/diaclin.26.2.77.

5. Danaei G, Finucane MM, Lu Y, Singh GM, Cowan MJ, Paciorek CJ, et al. National, regional, and global trends in fasting plasma glucose and diabetes prevalence since 1980: Systematic analysis of health examination surveys and epidemiological studies. Lancet. 2011; 378:31-40. doi: 10.1016/S01406736(11)60679-X.

6. Mathers CD \& Loncar D. Projections of global mortality and burden of disease from 2002 to 2030 . PLoS Med. 2006; 3:442-453. doi:https://doi.org/10.1371/journal. pmed.0030442.

7. Wild S, Roglic G, Green A, Sicree R \& King H. Global prevalence of diabetes estimates for the year 2000 and projections for 2030. Dia Care. 2004; 27:10471053. doi:https://doi.org/10.2337/diacare.27.5.1047.

8. Basit A, Hydrie MZ, Hakeem R, Ahmed K. Prevalence of diabetes, impaired fasting glucose and associated risk factors in a rural area of Baluchistan province according to new ADA criteria. J Pak Med Assoc. 2002; 52:357-360. PMID:12481676.

9. Resnikoff S, Pascolini D, Etya'ale D, Kocur I, Pararajasegaram R, Pokharel G P, et al. Global data on visual impairment in the year 2002. Bull of the World Health Organ. 2004; 82:844-851. doi:/S004296862004001100009 .

10. Pascolini $D$ \& Mariotti SP. Global estimates of visual impairment 2010. Br J Ophthalmol. 2012; 96:614-618. doi: 10.1136/bjophthalmol-2011-300539.

11. Frick $K D$ \& Foster $A$. The magnitude and cost of global blindness: An increasing problem that can be alleviated. Am J of Ophthalmol. 2003; 135:471-476. PMID:12654362.

12. Rowley W. R, Bezold C, Arikan Y, Byrne E. \& Krohe S. Diabetes 2030: Insights from yesterday, today, and future trends. Population health management. 2017;
20:6-12. doi:https://doi.org/10.1089/pop.2015.0181.

13. Fong D S, Aiello L P, Ferris $F L$ \& Klein R. Diabetic retinopathy. Dia Care. 2004; 27:2540-2553. doi:https:// doi.org/10.2337/diacare.27.10.2540.

14. Tziomalos K, Athyros VG. Diabetic nephropathy: new risk factors and improvements in diagnosis. The review of diabetic studies: RDS. 2015;12(1-2):110. Doi:10.1900/RDS.2015.12.110.

15. Rema M \& Pradeepa R. Diabetic retinopathy: An Indian perspective. Indian J Med Res. 2007; 125:297310. PMID: 17496357.

16. Lee R, Wong T Y \& Sabanayagam C. Epidemiology of diabetic retinopathy, diabetic macular edema and related vision loss. Eye Vis (Lond). 2015; 2:1-25. Doi: 10.1186/s40662-015-0026-2.

17. Yau JW, Rogers SL, Kawasaki R, Lamoureux EL, Kowalski JW, Bek T, et al. Global prevalence and major risk factors of diabetic retinopathy. Dia Care. 2012; 35:556-564. Doi: 10.2337/dc11-1909.

18. Hills AP, Arena R, Khunti K, Yajnik CS, Jayawardena R, Henry CJ, Street SJ, Soares MJ, Misra A. Epidemiology and determinants of type 2 diabetes in south Asia. The Lancet Diabetes \& Endocrinology. 2018 Dec 1;6(12):966-78. Doi: 10.1016/S2213-8587(18)30204-3.

19. Oza-Frank R, Ali MK, Vaccarino V and Narayan KMV. Asian Americans: Diabetes prevalence across US and World Health Organization weight classifications. Dia Care. 2009; 32:1644-1646. Doi: 10.2337/dc09-0573.

20. Hermans MP, Ahn SA, Sadikot S \& Rousseau MF. High rates of atherogenic dyslipidemia, $\beta$-cell function loss, and microangiopathy among Turkish migrants with T2DM. Diabetes \& Metab Syndr: Clinical Research \& Reviews. 2019; 13:716-720. doi:https://doi. org/10.1016/j.dsx.2018.11.049.

21. Jin G, Xiao W, Ding $X, X u X, A n L$, et al. Prevalence of and risk factors for diabetic retinopathy in a rural Chinese population: The Yangxi eye study. Invest Ophthalmol Vis Sci. 2018; 59:5067-5073. doi:https:// doi.org/10.1167/iovs.18-24280.

22. Jamal D, Qureshi MB, Khan AJ, Khan MD, Ahmad $\mathrm{K}$. Prevalence of diabetic retinopathy among individuals screened positive for diabetes in five community-based eye camps in northern Karachi, Pakistan. J Ayub Med Coll Abbottabad. 2006; 18:40-43. PMID:17348311. 
23. Mumtaz SN, Fahim MF, Arslan M, Shaikh SA, Kazi U, Memon MS. Prevalence of diabetic retinopathy in Pakistan: A systematic review. Pak J Med Sci. 2018; 34(2):493-500. Doi: https://doi.org/10.12669/ pjms.342.13819.

24. Triebel J, Macotela Y, Escalera GMDL \& Clapp C. Prolactin and vasoinhibins: Endogenous players in diabetic retinopathy. IUBMB Life. 2011; 63:806-810. Doi: 10.1002/iub.518.

25. Sacks DB. Carbohydrates in Tietz textbook of clinical chemistry and molecular diagnostics. $4^{\text {th }}$ ed. Burtis CA, Ashwood ER and Bruns DE. Elsevier Saunder, USA; 2006.pp.837-901.

26. Yasmeen F, Mumtaz A, Adhami SZ \& Qureshi SA. Comparison of caption exchange HPLC and Immunoturbidimetric method for determination of $\mathrm{HbA}_{1}$ c. Biomedica. 2011; 27:161-165. Doi: www. thebiomedicapk.com/articles/274.pdf.

27. Garg S, Davis RM. Diabetic retinopathy screening update. Clin Diabetes. 2009; 27:140-144. Doi:10.2337/ diaclin.27.4.140.

28. Ha M, Choi S Y, Kim M, Na J K \& Park Y H. Diabetic nephropathy in type 2 diabetic retinopathy requiring pan retinal photocoagulation. Korean $\mathrm{J}$ Ophthalmol 2019; 33:46-53. Doi:10.3341/kjo.2018.0034.

29. Thapa R, Bajimaya S, Sharma S, Rai BB \& Paudyal G. Systemic association of newly diagnosed proliferative diabetic retinopathy among type 2 diabetes patients presented at a Tertiary Eye Hospital of Nepal. Nepal J Ophthalmol 2015; 7:26-32. Doi: https://doi.org/10.3126/nepjoph.v7i1.13163.
30. Shokoofeh B, Nasser S, Abrishami M \& Haleh R. Serum prolactin level and diabetic retinopathy in type 2 diabetes. J Diabetes Metab. 2012; 3:173-175. Doi:10.4172/2155-6156.1000173.

31. Jin P, Peng J, Zou H, Wang W, Fu J, Shen B, et al. A five-year prospective study of diabetic retinopathy progression in Chinese type 2 diabetes patients with "well-controlled" blood glucose. PLoS ONE. 2015; 10:1-11. Doi:10.1371/journal.pone.0123449.

32. Rema M, Premkumar S, Anitha B, Deepa R, Pradeepa R, Mohan V. Prevalence of diabetic retinopathy in urban India: the Chennai Urban Rural Epidemiology Study (CURES) eye study, I. Investigative ophthalmology \& visual science. 2005 Jul 1;46(7):2328-33. Doi:10.1167/ iovs.05-0019.

33. Nathan DM for the DCCT/EDIC Research Group. The diabetes control and complications Trial/ Epidemiology of diabetes interventions and complications study at $\mathbf{3 0}$ Years: Overview. Dia Care. 2014; 37:9-16. Doi: 10.2337/dc13-2112.

34. United Kingdom Prospective Diabetes Study Group (UKPDS). Intensive blood glucose control with sulfonylurea or insulin compared with conventional treatment and risk of complications in patients with type 2 diabetes (UKPDS 33). Lancet. 1998; 352:837853. PMID:9742976.

35. Ismail-Beigi F, Craven T, Banerji M A, Basile J, Calles $\mathrm{J}$, and Cohen $\mathrm{R}$ et al. Effect of intensive treatment of hyperglycemia on micro vascular outcomes in type 2 diabetes: An analysis of the ACCORD randomized trial. Lancet. 2010; 376:419-430. Doi: 10.1016/S01406736(10)60576-4.

\begin{tabular}{|c|c|c|c|}
\hline \multicolumn{4}{|c|}{ AUTHORSHIP AND CONTRIBUTION DECLARATION } \\
\hline Sr. \# & Author(s) Full Name & Contribution to the paper & Author(s) Signature \\
\hline $\begin{array}{l}2 \\
3 \\
4\end{array}$ & $\begin{array}{l}\text { Syed Munawar Alam } \\
\text { Sagheer Ahmed } \\
\text { Shazia Bano } \\
\text { Shahneela Perveen }\end{array}$ & $\begin{array}{l}\text { Conceived, design, did } \\
\text { statistical analysis and edited } \\
\text { the manuscript. } \\
\text { Data collection and helped in } \\
\text { manuscript writing. } \\
\text { Data collection and helped in } \\
\text { statistical analysis. } \\
\text { Data collection and helped in } \\
\text { critical review of final draft of } \\
\text { manuscript. }\end{array}$ & \\
\hline
\end{tabular}

